\title{
Web Triad: the Impact of Web Portals on Quality of Institutions of Higher Education - Case Study of Faculty of Economics, University of Ljubljana, Slovenia
}

\author{
Ales Popovic, Jaka Lindic, Mojca Indihar Stemberger, \\ and Jurij Jaklic \\ University of Ljubljana, Slovenia
}

\author{
ales.popovic@ef.uni-li.si, jaka.lindic@ef.uni-li.si, \\ mojca.stemberger@ef.uni-lj.si, jurij.jaklic@ef.uni-lj.si
}

\begin{abstract}
Institutions of higher education are just like other organizations forced to adapt to the rapidly changing environment that brings many new challenges. There are several obstacles in the way of introducing e-learning in these institutions. We can divide them into technology-based and culturally-based. Many benefits of e-learning such as cost-effectiveness, enhanced responsiveness to change, timely content, flexible accessibility, and providing value to the customer are not based only on use of high technology. We cannot expect that the use of advanced technology is enough to change the way we work as human beings. Technologic solutions in the form of portals have been known for several years. A recurring problem has become the efficiency and usefulness of these solutions. Integration of dispersed sources is not sufficient. Individual users should obtain information in a variety of ways, including in a personalized way.

The paper will address the topic of using the Internet as a medium to achieve one of the primary goals of institutions in higher education; that is quality improvement. We will show the influence of the e-learning environment on achieving this goal. The model has also been tested in practice, at the Faculty of Economics at the University of Ljubljana. This case has also proved that cultural changes never take place over night.
\end{abstract}

Keywords: efficiency, e-learning, personalization, quality improvement, technology, web portals

\section{Introduction}

Educational institutions are facing intense pressure to increase operational efficiency and effectiveness demonstrated in a measurable increase in student and faculty achievement. Institutions are also forced to adapt to the quickly changing environment (growing student population, greater community responsibility, cultural changes, lifelong learning, greater technology accessibility, new entrants and stronger existing competition). A factor of big influence is heterogeneity (students, their information and telecommunication equipment, their ethnologic background, knowledge). Disappearing borders and uniting Europe, the idea of perfect faculty and students' mobil-

Material published as part of this journal, either on-line or in print, is copyrighted by Informing Science. Permission to make digital or paper copy of part or all of these works for personal or classroom use is granted without fee provided that the copies are not made or distributed for profit or commercial advantage AND that copies 1) bear this notice in full and 2) give the full citation on the first page. It is permissible to abstract these works so long as credit is given. To copy in all other cases or to republish or to post on a server or to redistribute to lists requires specific permission from the publisher at Publisher@InformingScience.org ity, competition in the field of education, etc. are becoming important factors even in countries where this had not been the case before.

To be competitive, institutions of higher learning must constantly venture into new and innovative methods and radically change the educational 
outlook. They are forced to adapt the knowledge and experience from the business world. They need to realize that it is not just core functions but also the supporting functions that need to be addressed. New approaches to teaching pose challenges and opportunities to both faculty and administrators. E-learning as seen today is mostly related to, or even based on, the use of high technology (high bandwidth, new powerful hardware and software). Another important issue is a lack of IT resources in educational institutions, both in the form of technical staff and technology.

In the next section of this paper, we tackle the peculiarities of the educational environment in light of e-learning. In section 3, we present a model that illustrates the impact of web portals on the quality of institutions of higher education. Section 4 presents a case study of our institution in which the presented solution was carried out. In the last section we summarize our experiences and emphasize critical success factors for successful development, implementation, and use of the presented solution.

\section{Educational Environment and E-Learning}

E-learning is an upgrade to teaching and learning. In its broadest definition, e-learning includes instruction delivered via all electronic media including the internet, intranets, extranets, satellite broadcasts, audio/video tape, interactive TV, and CD-ROM (Govindasamy, 2002). If we redefine this definition, we would define e-learning as the use of the Internet and other related technologies to deliver, support, and enhance teaching, learning, and assessment. But there are several obstacles in the way of introducing e-learning in higher education institutions. We can divide them into technology-based and culturally-based. Technology vendors are focusing mainly on high technology solutions that offer interactive learning materials, usually in the form of multimedia and lectures delivered via video conferencing. The key difference between traditional class-based educational process and e-learning process lies in the medium carrying the educational process (Hamid, 2001). In a traditional environment, a teacher has full control over educational environment whereas in an e-learning environment from pedagogical viewpoint this is not the case due to smaller possibilities of adaptation.

As already mentioned, there are several issues related to e-learning focusing on these topics. The first issue is technology-based. Although the penetration of broad bandwidth connections to the Internet is rising, it is still not high enough to allow us to base e-learning on it. In the USA, more than $67 \%$ of users are still connected to the Internet with connection speed up to $56 \mathrm{Kbps}$ (Web Site Optimization, 2003). In Slovenia only 21\% of users are using broadband connections (Slovenian Ministry of Information Society, 2004). There are also other technology-based obstacles, such as the need for special software and/or hardware. Special software is usually needed for creating multimedia-learning materials. When considering the creation of multimedia materials, one must take into account the need for special knowledge, special know-how, and experiences. With e-learning, as usually seen, it is not enough to know the subject but it must also be presented well. A teacher has to have extra knowledge of how to prepare online multimedia materials. E-learning materials are much more than just converting or transferring books or any other printed material to an interactive medium (Hamid, 2001). Although it might seem like technology is the key problem, in our opinion, people are.

The traditional way we gain knowledge and formal education has been the same for a very long time. It is irrational to expect that the use of advanced technology is enough to change the way we work as human beings. Cultural changes never take place over night.

Nevertheless, there are many benefits of e-learning including cost-effectiveness, enhanced responsiveness to change, consistency, timely content, flexible accessibility, and providing value to the customer (Sanderson, 2002). The major benefits are not based on the use of high technology. The primary role of e-learning, as we see it, is to support effective communication between stu- 
dents, faculty, and administration resulting in more effective and efficient teaching, learning, and assessment.

We propose the introduction of web portals as a solution. As realized in the business world, we are not only facing abundance of information on the Internet but also inside organizations. The development of technology adds to the quantity of the data available. Web portals have been suggested as a solution to this problem (Govindasamy, 2002). By centralizing information, streamlining business process, and connecting people for meaningful collaboration, enterprise portals can improve operational efficiency, reduce costs, and build loyalty (Voth, 2002). Too often, portals are understood only in terms of technology, which represents only one segment or view. Although we agree with Means and Schneider (in Lewis, 2002) who predict a 'technology driven future', where world-renowned academic content providers, teams of 'edutainment' experts and continuous updating and investment of resources transform higher education, we believe, that at this point in time, content plays a crucial role. Based on some estimates, technology only adds up to a third of total work related to good portal setup (Nielsen, 2003). What differentiates portals from static web pages is their ability to include data from different sources, in different forms and formats, and present them in a unified consistent way through a single access point (Nielsen, 2003). From the user's viewpoint this means that portals represent a single access point for all of the user's information needs in a specific area. In the case of educational institutions, this can represent a student portal which supports all of the student's activities in the educational process without the need for students to use different systems (e.g. systems to access study material, students' office news, exams signup etc.). Among typical functions included in a portal are security, network, administrative tools, search tools, tools for content management, personalization, expandability and ease of use (Raol, Koong, Liu, \& Yu., 2002).

The most important purpose of building web portals is to improve efficiency and effectiveness of employees. Efficiency is being improved through better usability (faster and more accurate information retrieval, faster and more correct task accomplishment) and through reduction of redundant data (data is entered in the system once, where and when it occurs). Better efficiency of employees has several positive influences. Instead of carrying out routine tasks they make more creative use of their time (for getting new knowledge, optimizing other processes, etc). As many researches in the field of organizational theory showed, reducing routine tasks leads to a better job satisfaction. Reducing routine tasks leads to improved effectiveness of an individual and of the organization as a whole. For portals to actually lead to better quality, it is important to also take care of other aspects, especially their content and practicability.

\section{Model of the Impact of a Web on the Quality of Higher Education Institutions}

When implementing different solutions it is often hard to prove a direct connection between investments or their results (implemented solutions) and successfulness (measurable results). The remaining part of this section presents a proposed model for the impact of a web portal on the quality of institutions of higher education. Quality of an institution of higher education can be defined in different ways. In our model, it is composed of different areas, such as:

- Quality of the study and acquired knowledge (affects future employment of students);

- Quality of pedagogical process (affects the transition of students between study years and the satisfaction of the students);

- Quality of research (number of papers in important publications); 
- Connection with business environment and broader society (co-operation with guests from business sphere, transfer of knowledge and research results in practice, increased flow of knowledge and ideas);

- Connection with international environment (international exchange programs for students and teaching staff) and

- Business success (commercial research, consulting and corporative educational activities).

Web solutions with their individual elements allow improvements in different areas. These improvements directly or indirectly enable quality improvement of an institution. In the proposed model, portals can contain a variety of contents that can be classified into three groups: pedagogical and research, informational and communication, and administrative (Figure 1). The first group includes elements related to the course planning process, course management, and course collaboration. Teachers are able to publish news, prepare term plans, and use document system to publish course materials. Teachers, students, and external collaborators (e.g. guests from business sphere) can collaborate with each other in on-line discussions. Students are able to access on-line study materials and sources and take web-based exams. With the help of web surveys carried out at the end of each course, the gathered data is promptly analyzed and results delivered to faculty and staff to provide feedback for educational process improvement.

Informational and communication elements include different information connected with the study (e.g. news from courses, important assignment dates, changes in teachers' office hours, exam examples and practice etc.) and information regarding corporate relations, international relations, and career services (e.g. news and events from International office, Centre for Management Development and Training, Business Projects and Case Study Centre, Center for Student and Career Services).

Lastly, groups of portal elements cover administrative processes. These include students signing up for final exams, reviewing their current and past grades, filling out administrative forms and ordering various certificates (e.g. certificates of enrolment, certificates of passed exams, GPA etc.), reviewing available jobs from partners, or looking for available internships. Employees can manage their business email accounts, record their working time, and review received assignments.

Individual elements contribute to the quality of an institution in different ways and to different extents. Thus, administrative elements can significantly contribute to faster and more efficient performance of administrative processes. In this way employees' workload is reduced, students' satisfaction rises and costs decrease. Informational elements, for example, improve communication with all stakeholders and thus positively affect process performance. With the help of Web surveys, the institution can track the quality of pedagogical work and the work of other support staff. Based on the gathered results, the institution can continuously improve its processes. Because of simplified routine tasks, teachers are able to dedicate more of their time to the content of their pedagogical and research work and the support staff can better assist them. 


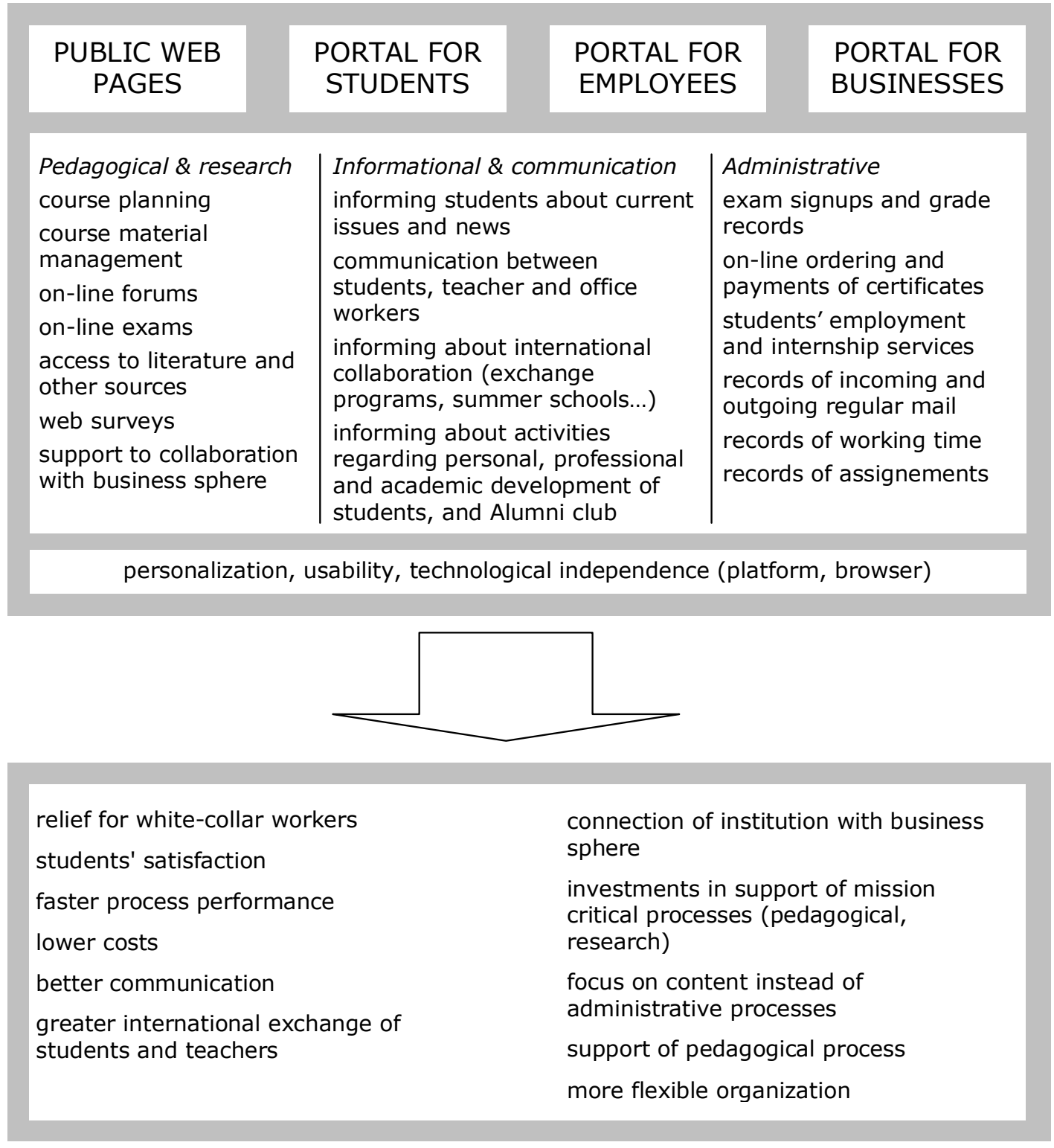

Figure 1: Model of web portals' impact on quality of institutions of higher education

\section{Web portals at FELU - Web Triad}

The Faculty of Economics at the University of Ljubljana (FELU) is one of the largest institutions of higher education in Slovenia with over 11,000 students (undergraduate and graduate) and with just over 220 employees, 150 of whom are teachers. The FELU has a long tradition in research and education. Development and modernization of teaching and research work have been priorities at the Faculty from its very beginning. Its vision is to become a prominent member of the group of the top quality European business and economics schools with a clearly distinctive meaning for the Slovene economy and the economy of the Central and South-Eastern Europe, as well as the highest international teaching and research standards that will make it - together with its students and graduates - appealing to both the Slovene and international economies (FELU, 2004). This vision can only be achieved through a permanent increase of the quality of the institution as a whole. In the current working conditions, about 75 students per teacher, it is very hard to 
dedicate enough time to individual students and assure appropriate quality of study. Improved quality with the high student:teacher ratio can only be achieved with appropriate IT support.

To overcome the problem, FELU uses several approaches, especially those supported by IT (Internet and web portals). The web of FELU supports the implementation of the vision, mission, and strategy. The design of the portals is closely related to the strategy of FELU, which represents ways of accomplishing its vision (Figure 2).

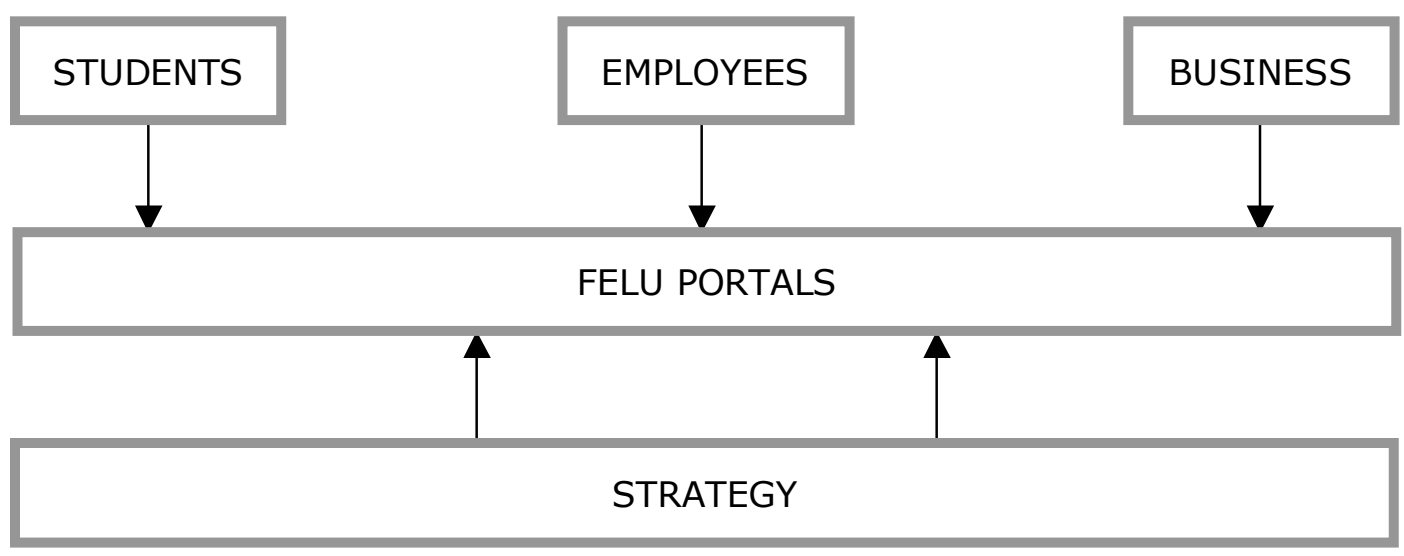

Figure 2: Portals for different publics support FELU's strategy

\section{Developing the Portals}

Web portals at FELU offer efficient ways to support improved quality of the institution and are fully integrated into FELU's information system. The beginnings of the portals date back to 1995 when FELU's first web pages were created for the needs of distance education learning. These pages offered useful information about the study, courses, and exams. During this period, the first software for exam signup and grade reviews on the web was developed (Indihar Stemberger \& Jaklic, 1999).

FELU used the experiences gained from developing the distance education web pages when developing the first pages for its regular study programs. These pages were the first step to what would become the FELU portals. When developing the portals, the needs of the students and the requirements of other users had the highest priority

The use of portals in pedagogical process and other administrative processes is strongly supported and stimulated by FELU management. The management is also actively involved in designing new features and content of the portals. Due to the involvement of management, the use of portals has become an everyday business issue to almost every employee at FELU. FELU's management sees these portals as technological support in the process of vision fulfillment and mission accomplishment.

Actively involved school management, good understanding of user requirements, and thoroughly planned content management were the key factors that contributed to richer portals. Portals bring together the different contents for different target publics. Today, the FELU portals (Figure 2) can be seen as a web triad: a portal for students, a portal for employees, and a portal for businesses. Although it is presented as a single portal, it can be also viewed as three unique portals. Each user has a role and the portal adjusts itself to particular user's needs. Despite having specific content in each of them, there is always general information about the school, current news, and events, courses, and pedagogical staff available to visitors. One of the important characteristics about the portals is the interconnection among the individual parts. From the early days, the portals' design and development has been led by the idea of entering any information into the system at the place 
Popovic, Lindic, Indihar Stemberger, \& Jurij Jaklic

at which it occurs. Thus, the portals assure that the information is entered in a timely fashion and is always up-to-date.

\section{Portal Features}

The portal for employees and other collaborators was introduced in 2001. Employees can manage a variety of tasks that are used on a daily basis as well as those that are carried out irregularly. A high degree of content personalization for this portal is typical. The content is adaptable to different groups of users (e.g. teachers, support staff at student offices, staff in other organizational units). Each individual user can further customize the content to meet his/her needs regardless whether these needs are temporary or permanent. The most important portal features are:

- Document and news management system. Employees are able to view current and past news, and post their own. The document system allows users to post their own documents (regulations, guidelines, minutes, reports), along with document versioning and permission assignments for accessing the documents.

- Staff communication. This was one of the first implemented features of the portal. Employees can communicate on a personal basis, between established groups (e.g. management, departments, other organizational units), or on the corporate level.

- Pedagogical activities. Teachers can, in a simple and efficient way, manage their own pedagogical activities, especially course management. This includes real time editing of course general information (simple independent arrangement of data on courses, such as course description, course literature etc.), publication of materials and notices for students, students' frequently asked questions management, management of time plans for classes and practical work as well as of courses' forum.

- Organizational unit content management. Staff from organizational units (e.g. International Office, Students' Career Centre etc.) can easily manage the general design and content of their presentation pages, including news and events management, entries for limited events, and monthly and yearly reports.

- Access to research data. From a single point, each employee can access different research data, such as yearly balance sheets from Slovenian companies, central library, European Documentation Centre, and data from different institutes hosted at FELU.

- Access to financial records and other administrative records. Connected directly to the accounting department at FELU the portal allows its users to view their financial transactions for research spending and, providing they have permissions to do so, to access financial records for projects they are assigned to. Web administrative records include access to job presence recording services for non-pedagogical staff, records for incoming and outgoing mail at FELU, records for own assignments, review other staff assignments, records for current and past projects, etc.

As Ives (2002) pointed out in order for the implementation of the portals to be successful, they must be integrated into business processes. Our case supports this thesis as the portal for employees is used a lot since many of the regular processes (pedagogical and non) were moved to the web and were discontinued in their classical form (e.g. job presence for non-pedagogical staff, assignments records, and financial records).

The portal for students, also known as Student-net, was introduced at FELU in early months of 2003. Student-net offers students an entry point to access the content and tools they need in their studies. They can thus find essential information, news, notices, documents, and study materials in one place; they can perform administrative procedures, such as registering for exams, review- 
ing their own records, accessing research data, and communicating with teachers. As for the employees' portal, Student-net has also a high level of personalization. The portal is available for both undergraduate and graduate students. The features of Student-net include:

- General news and notices. Students are able to access general news and other theme news (e.g. news from International Office, Internship news, Job listings) from a single point in Student-net.

- Document system. It allows students to access various documents related to their studies (timetables, regulations, reports, administrative forms etc.).

- Communication system. Enables communication between students (through private messages), groups of students, and between students and teachers through a web based mailbox integrated into the portal. Part of this system is also a general-purpose forum where students can anonymously discuss different topics (including off-campus topics) and a module for sending suggestions and questions to different authorities at FELU (with an answer tracking option).

- Course management. Students have full control on what is going on with the courses they are attending (both mandatory and elective courses). Each student can customize his/her own view about what information (e.g. news, course materials etc.) is going to be displayed and when the last change was made. The course management module is one of the most important modules in the student portal. It provides connections among the courses' web pages, their news and study materials (e.g. PPT presentations, exercises, exam examples etc.), course online discussions, web-based exams, and communication between students attending each course.

- Virtual office. Through the virtual office, students are directly connected with the student office information system and with their working processes. This way they can get prompt (general and user specific) notifications from the office, communicate directly with the office, sign up for exams, check the status of their various applications, and register for courses.

- Career Centre. Students can access the Career Centre information system to enter their curriculum vitae $(\mathrm{CV})$ and thus advertise their availability to partner companies seeking new workers. When entering CVs, most of the information (e.g. personal information, grades, achievements, completed seminars and extra courses, case studies etc.) is automatically collected from other FELU's units and portals since the systems are interconnected.

- Study resources. Access to most of the resources students might need for their studies is conveniently integrated in Student-net. Links to these resources are updated regularly. Among the resources available are the Data Analytical Centre at FELU, European Documentation Centre, and data resources in Slovenia and abroad.

- Review of current activities at FELU. This module includes current activities, such as seminars, workshops and other events.

The portal for businesses is the newest part of the web triad. Its main goal is to support the collaboration between FELU and business partners at different levels through the various units at FELU. Some parts of the portal are still under development; however, the main features are already established and available to corporate partners. These features include:

- Communication with different FELU units. FELU collaborates with the business sphere through different units, such as: the Research Centre, the Business Project and Case Study Centre, and the Centre for Management Development and Training. By using the portal, 
companies can directly communicate with individual units, exchange messages and documents, and update their contact information.

- Tracking business, research and academic collaboration. Companies can easily and efficiently track their collaboration with each individual FELU organizational unit. This includes various projects, seminars, case studies, guest participation at FELU's courses, scheduled student visits at company premises etc.

- Selection and tracking of potential job candidates. By directly accessing students' CVs, companies can select and track potential candidates for future employment or internships, and communicate with selected students.

By introducing the portal for business, FELU has strengthened its connection with the corporate world. Through the portal, corporate partners have a single access point to an integrated management system that provides for many levels of collaboration.

\section{Implementation}

Implementation of portals is component-oriented with special emphasis on user benefits. Every feature included in the portal has to have some kind of added value for the user. Portals are developed from a wide range of content units called portlets. Portlets are independent and can be freely combined into an adaptable web page. Portlets can be found in form of:

- Regular web links (static or dynamically created; e.g. a link carrying user's ID for user's records retrieval),

- Simple web forms (e.g. search form for employees, documents in document system, news search etc.),

- Other web contents (e.g. combined with access authorization a portlet is used to retrieve financial information from accounting IS).

The portlets are then combined into categories. A category is a content-independent part in a portal (e.g. pedagogical activities, research activities, contacts, administrative tasks, news and events etc.). A user is assigned to a group and each group has access to its categories. Category contents are chosen to provide the best support possible for the processes each category covers. The content each user sees (directly or indirectly through the group membership) is administered by the portal administrator. It is important to note that this position is a content administrator - editor $\mathrm{He} / \mathrm{she}$ chooses the categories each user has access to, in which category the content will be available, and which content will be displayed as the default. It is up to the user to decide whether or not use a category or to simply remove it from viewing. There is only a small portion of users who actually take the time to minutely study the possibilities they have to adapt the portal. It is, therefore, of vital importance for the administrator to effectively define the users' roles and available contents to which users have access. Thus, the administrator does not consider one of the key problems that portals want to solve - the abundance of information. It is on the administrator to choose the variety of possibilities to offer to a user. Information must be selected in a way that warns a user of possibilities of the intranet or extranet in order to achieve the highest possible level of productivity.

Portlets are the foundation for portal personalization. Personalization is especially important because of the functions every portal should have, such as autonomous individual personalization, powerful search engine, support for collaboration and community, proper security, support for content management (Raol et al., 2002). Portals at FELU are already personalized and adapted to individual user roles but they also allow autonomous individual personalization. Users can, in accordance with the last two levels of security (access to categories and access to individual port- 
lets), optionally sort portlets and categories, turn them on and off, and adjust some of their contents (e.g. students can choose which courses to display in the course portlet within study category).

The portals use multilevel security protection and central control. The first level of security is access to the portal. At login, the system verifies to which groups the user belongs and to which portlets the user has access. Portlets that the user does not have access to are not displayed within a category, even though the user might have access to that specific category.

When developing the portals, great attention is paid to the specific nature of the academic environment, especially to the heterogeneity of users accessing the portal from various locations and having different technologic setups. We strive for the simplest technology possible available to achieve a certain goal. Development is especially concentrated on independence of solutions of included information communication technologies - especially on the user's side.

\section{Use of portals}

The use of portals has been very effective at FELU. One of the major reasons is the support from management, especially its involvement in the portal design, such as applications and contents, and encouraging employees to use the portal. As of early December 2004, more than $88 \%$ of employees ( $83 \%$ of pedagogical staff) use the portal on regular basis, at least several times per week. More than $98 \%$ of all students are using the Student-net. In the last year, they made an average of 156 visits each. Although the Student-net is highly personalized, 23\% of the students performed additional personalization. This is an indication that, regardless of how good automatic personalization is, there is still a need to allow the user to additionally personalize the portal according to his or her individual needs and wishes. It is also important to emphasize that both the employee and student portals connect different aspects of FELU activities, not only e-learning. Some of these aspects are connections with the Students' International Office and the Centre for Student Development and Counseling. At the end of 2003, a usability study of the student portal was carried out. The research also included the web sites of two other Slovene faculties to perform benchmark testing. Usability study was conducted using usability testing, guideline checklist, expert review, page layout analysis, mystery shopping method, interviews. For usability testing 5 scenarios were prepared. They were performed by both novice and experienced users. The results showed some minor usability problems of the Student-net that influenced its learnability. The most important difference shown was in the area of productivity of experienced users. Our students outperformed their colleagues from the other two faculties by 69 to $78 \%$ (measured in the time needed to complete a typical scenario).

\section{Conclusions}

All too often we are influenced by high technology vendors arguing that we have a high technology user base that is big enough. At this moment reality is far from what vendors would like to make us think. We do see broadband as an important base of e-learning. However, in our opinion, technology is not the most important limitation of e-learning. It is the cultural change that is needed. It is a question of changing what people expect of learning and most of all how they engage in the learning process. E-learning is much more than just transferring printed material to its electronic form.

At this time, we see e-learning primarily as a form of improving communication. Through a case study at FELU, we described a possible solution - the use of a web portal. Portals, when properly designed, increase both effectiveness and efficiency of an institution. As shown through this case study, they can be used as an effective communication tool. Our final goal should be a reduction of costs of opportunities lost due to poor competitive advantage. We can achieve this by giving 
the necessary information to the user when they need it. Personalization plays an important role in this task.

The use of a portal in a highly heterogeneous environment proved not only to be sensible but also necessary. Because of the ease of use and positive influence on productivity, users quickly realized the benefits of portals use. Through extensive top management support and user initiative, we were able to create many contents and gain the acceptance of the majority of users in a relatively short time. The critical factors for successful development, implementation, and use of the presented solution were:

- Management support,

- Information is entered into the system where it occurs and is therefore prompt and up-to-date,

- Ease of use and intuitive user interface, and

- Proven positive effects on productivity, which influenced users to actively contribute to the development of portals' features.

In the future we want to add new features to the portals by following the trends in IT fields. Currently a feasibility study about mobile device access to portal contents is being carried out.

When trying to improve the quality of an institution of higher education through the implementation and use of web portals it is essential work with the vision and strategic goals of the organization when designing the solutions. Only in this way will the proposed solutions actually suit the needs of the organization and its users.

\section{References}

Govindasamy, T. (2002). Successful implementation of e-learning: Pedagogical considerations. The Internet and Higher Education, 4, 287-299.

Hamid, A. A. (2001). e-Learning: Is it the "e" or the learning that matters?. The Internet and Higher Education, 4, 311-316.

Indihar Stemberger, M. \& Jaklic, J. (1999). What kind of web based information system students need? Proceedings of $4^{\text {th }}$ International Educational Computer Conference - MIRK '99, 110-115.

Ives, W., \& Cheese, P. (2002). Realizing the promise of portals. Researching Technology Issues, 5(3), 2023.

Levis C. (2002). Driving factors for e-learning: an organizational perspective. Perspectives, 6(2), 50-54.

Nielsen, J. (2003). Jakob Nielsen's alertbox, intranet portals: A tool metaphor for corporate information. Retrieved March 31, 2003, from http://www.useit.com/alertbox/20030331.html

Raol, M. J., Koong, K. S., Liu, L. C. \& Yu C. S. (2002). An identification and classification of enterprise portal functions and features. Industrial Management \& Data Systems, 102(7), 390-399.

Sanderson, P. E. (2002). E-learning: strategies for delivering knowledge in the digital age. The Internet and Higher Education, 5, 185-188.

Slovenian Ministry of Information Society. (2004). Slovenia has reduced the lag in Internet usage compared to European Union countries (in Slovene). Retrieved on June 26, 2004, from http://mid.gov.si/mid/mid.nsf/0/6327C8407CE4276BC1256E240044D504

University of Ljubljana - Faculty of Economics. (2004). Mission and Vision. Retrieved December 10, 2004, from http://www.ef.uni-lj.si/en/info/misVis.asp

Voth D. (2002). Why Enterprise Portals are the Next Big Thing. E-learning. October 2002, 25-29. 
Web Site Optimization. (2003). Web Connection Speed Trends - United States Users. Retrieved June 15, 2004, from http://www.websiteoptimization.com/bw/0301.html

\section{Biography}

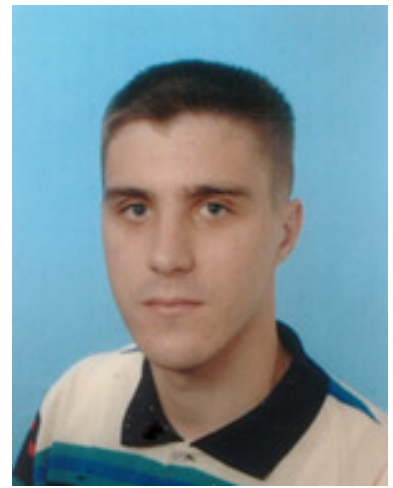

Ales Popovic, B. Sc., is an assistant lecturer for Information Management at Faculty of Economics, University of Ljubljana, Slovenia. His pedagogical work in the past five years was oriented mainly in preparing and performing computer workshops (lab lectures) for undergraduate business students. His main research interest is concentrated around the question of influence of contemporary Information Technologies and Information Management as a whole on (better) business performance. Topics of interest in view of that include business informatization, business process modeling, business process simulation, elearning, and education in the field.

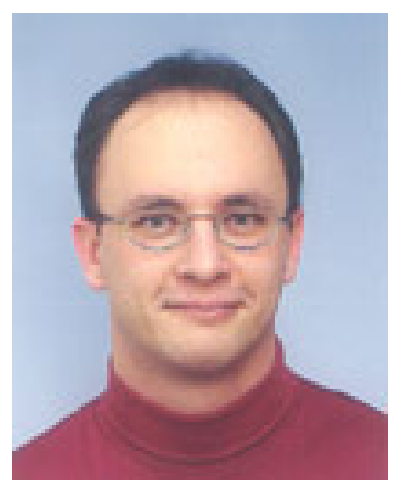

Jaka Lindič, M. Sc., is a teaching assistant at the Faculty of Economics, University of Ljubljana, Slovenia. His main research interests include e-business strategies and models, usability and overall quality of web sites. He has experience in the development of Faculty's online systems and corporate Web-based Information Systems. He also works as a consultant for e-business.

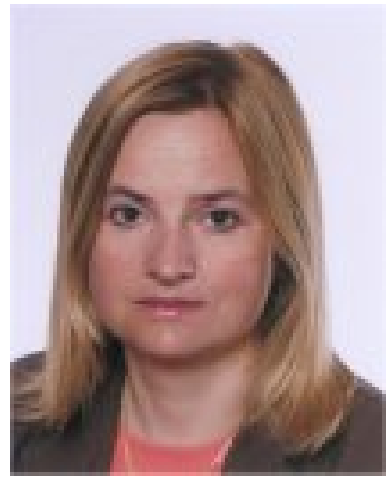

Mojca Indihar Stemberger received her Master in Computer and Information Science degree in 1996, and her Ph.D. in Information Science in 2000 from the University of Ljubljana, Slovenia. Currently she is an assistant professor at the Faculty of Economics, University of Ljubljana. Her research interests include business process renovation, e-business and decision support systems. She is a president of the Slovenian Informatics conference.

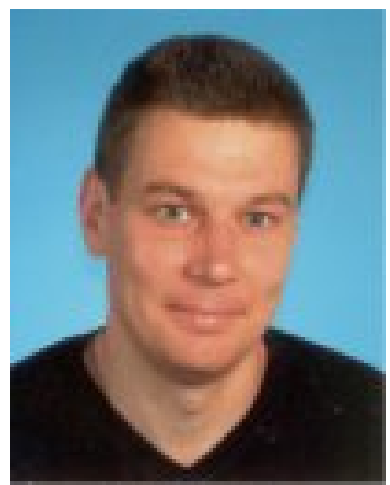

Jurij Jaklic received his Master Degree in Computer Science in 1992 from the University of Houston and his PhD in 1997 from the University of Ljubljana, Slovenia. Currently he is an assistant professor at the Faculty of Economics, University of Ljubljana. His main research interests are business process reengineering, business renovation, ebusiness, decision support systems, and data and business modelling. $\mathrm{He}$ is a member of the program committee at the Slovenian Informatics conference. 